\title{
THE POSSIBILITIES OF CONCEALED RECEIVING SYSTEMS*
}

BY

\section{A. Hoyt TAYLOR}

(Professor of Physics, University of North Dakota) $\dagger$

No one who has had any considerable experience with continuous wave receivers can fail to note the remarkably loose coupling which may be successfully employed between the antenna circuit and its secondary.

Some time ago, it occurred to the writer that even for long distance reception it ought to be possible to dispense with the antenna and ground connection by expanding the secondary circuit into a form which would cut sufficient magnetic lines in the wave to give, with a sensitive receiver, readable signals. The excuse for reporting these experiments is that while the principles involved are not new, the results obtained have been rather surprising, and indicate possibilities which may have been overlooked by some earlier experimenters. ${ }^{1},{ }^{2}$.

The secondary circuit of the receiving set at " $9 \mathrm{XN}$ " (Grand Forks, North Dakota) was accordingly replaced by a rectangle 10 feet ( 3 meters) square, of 40 turns of number 27 double cotton covered wire. ${ }^{3}$ The rectangle was hung up inside a room in a brick and steel building which is full of wiring conduits and gas, water, and steam piping.

Audible signals from "NAA" (Arlington, Virginia), "WSL" (Sayville, Long Island), "WGG" (Tuckerton, New Jersey), and "NAJ" (Great Lakes, Illinois), were received." The turns

* Received by the Editor, July 8, 1916. This paper will be followed in early issues of the ProceEdings by three papers by Commander Taylor on the use of ground wire systems. the elimination of strays, and remote control stations.-EDITOR.

$\dagger$ Now Lieutenant-Commander, United States Navy. January, 1914 .

2 Pickard, "Electrical Review," 50.

3 Diameter of number 27 wire $=0.0142$ inch $=0.36 \mathrm{~mm}$.

${ }^{4}$ (The distances from Grand Forks of each of the stations mentioned are respectively 1,210 miles $(1,950 \mathrm{~km}$.), 1,190 miles $(1,915 \mathrm{~km}$.), 1,170 miles $(1,885 \mathrm{~km}$.$) , and 620$ miles $(995 \mathrm{~km}$.) practically all over flat country, one moderately high mountain range intervening in the first three cases. Arlington is equipped with a 60-kilowatt are set and a 100-kilowatt spark set, Sayville with a 100-kilowatt alternator-frequency changer set, and Tuckerton with a 60-kilowatt arc set.-EDITOR.) 
of this rectangle were evidently too close together, giving a bad distributed capacity effect. A new rectangle with the wires wound side by side in a flat band gave better results, and a third one with 16 turns spaced about 2 millimeters $(0.08$ inch) apart gave such satisfactory reception of all waves from 2,500 meters up that it was decided to continue the experiments at the writer's home where the rectangle was hung up in a tree and arranged so that it could be rotated so as to take advantage of the directive effect. It was found unnecessary to have the lower wires more than 5 feet (1.5 meters) from the ground.

Figure 1 shows the complete receiving system. The adjustments are very simply made by simultaneous variation of the condenser $C$ and the plate circuit inductance $L$. The bulbs used

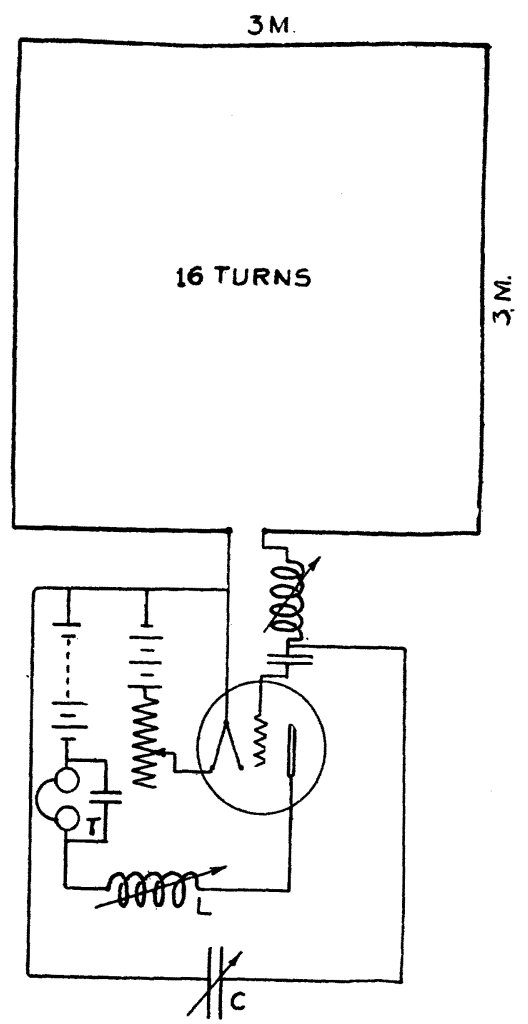

Figure 1-Wiring of Receiver

were cylindrical, with cylindrical plate, spiral grid, and two straight filaments, only one of which was used. Nineteen of these bulbs were tested, and only one found which with proper 
choice of high potential battery and heating current failed to give satisfactory results. The voltages used on different bulbs were found to vary between 22 and 40 volts, and the filament current from 0.78 ampere to 0.90 ampere. For any one bulb, the adjustments were exceedingly constant and certain of duplication. The writer regrets to report that attempts to measure audibilities by the shunted telephone method, using a Brandes 3,200 ohm telephone receiver, were not very successful, since the bulbs began to give the siren effect as soon as the shunt was reduced to between 100 and 300 ohms. Shunts were occasionally made with two receivers in series. For Arlington working on 6,000 meters by daylight, this shunt was usually about 200 ohms when they were working with "NBA" (Darien, Panama Canal Zone). The writer is of the opinion that such shunts cannot readily be translated into audibilities, since shunting a receiver unquestionably affects the conditions of oscillation in the bulb, and the effectiveness of the shunt depends on the pitch of the signal observed. Bulbs giving equally loud signals will shunt down to very different values.

Observations were begun in the latter part of April, 1916, and daylight signals from Arlington, Virginia; Key West, Florida; Darien, Panama Canal Zone; Sayville, Long Island; Tuckerton, New Jersey; Great Lakes, Illinois; New Orleans, Louisiana; San Diego, California; Bolinas, California, and South San Francisco, California, were always readily readable when the plane of the rectangle coincided with the direction from which the waves arrived. The distance from Darien is 3,000 miles $(4,800 \mathrm{~km}$.). During June and July, the strays prevented the reception of Bolinas and very often of South San Francisco. The most remarkable performance was the almost daily reception of the 2,500 meter mid-day time signals from Arlington up to date (July 6). The tone of the spark was destroyed, as it was absolutely necessary to have the bulb oscillating in order to get the signals.

The 7:30 P. M. Central time press reports sent out on the same wave length were copied nearly every day up to June 15 , altho it is broad daylight here at that hour.

In connection with these results it may be pointed out that the efficiency of a receiving system in the period of summer strays depends not so much on the absolute audibility of the signals as on their relative audibility as compared with strays and other disturbances. In this respect, the rectangle has a very great advantage. If the strays are equally distributed 
from all points of the compass, the rectangle, owing to its directivity, cuts out a considerable part of them.

The selectivity may of course be greatly increased by using a variable condenser in series with the rectangle and adding an inductive coupler. The set then becomes a standard set with the antenna and ground replaced by rectangle and variable condenser. The signals are about 50 per cent. stronger when all adjustments are carefully made, and the strays are a little weaker. Such an arrangement was used when working at night, when an arc light less than 300 feet $(100 \mathrm{~m}$.) distant created bad interference below 6,000 meters. With this standard and wellknown arrangement, however, the set loses the prime advantage of simplicity. The operation involves just twice as many adjustments.

Experiments were continued with two other rectangles, each of sixteen turns wound edgewise, or in the plane of the rectangle. One rectangle, having an area of 103 square feet $(9.57 \mathrm{sq} . \mathrm{m}$.) was hung against the east and west wall of a second floor room, and the other, of 77 square feet $(7.15 \mathrm{sq} . \mathrm{m}$.) area was hung against the north and south wall. Figure 2 shows the connection used. By closing the switch $S_{1}$ and throwing the switch $S_{2}$ to the left, the east-and-west rectangle could be used; by closing $S_{3}$ opening $S_{1}$ and throwing $S_{2}$ to the right the northand-south rectangle was in circuit; by opening $S_{1}$, throwing $S_{3}$ to the right and closing $S_{2}$ to the left both rectangles were in service, and so connected as to have directivity to the southeast. By reversing the connections of the north and south rectangle (by throwing $S_{3}$ to the left) the resultant directivity could be changed from northwest and southeast to southwest and northeast. With this arrangement signals from all points of the compass could be received with a fair degree of directivity.

This set permits most of the selective advantages of the single rotary rectangle in a convenient and easily concealed permanent installation. The rectangles may be readily concealed behind a tapestry or, if need be, inside of the wall, except in the case of steel structures where they could not be used inside for reception over distances greater than 500 miles (800 $\mathrm{km}$.) depending on the type of building and its surroundings.

An example of the usefulness of the two rectangle combinations may be cited. When Darien 19 degrees southeast from Grand Forks is sending at the same time as south San Francisco 58 degrees southwest, there is no interference even on the same wave length if the switch $S_{3}$ is thrown so as to give southwest 
directivity in the one case and southeast in the other. Similar results were obtained in eliminating interference between Arlington and Bolinas. The southeast combination eliminates San Diego while the southwest combination greatly weakened Arlington signals altho they were still readable. If Arlington and San Diego were sending simultaneously, they could readily be separated.

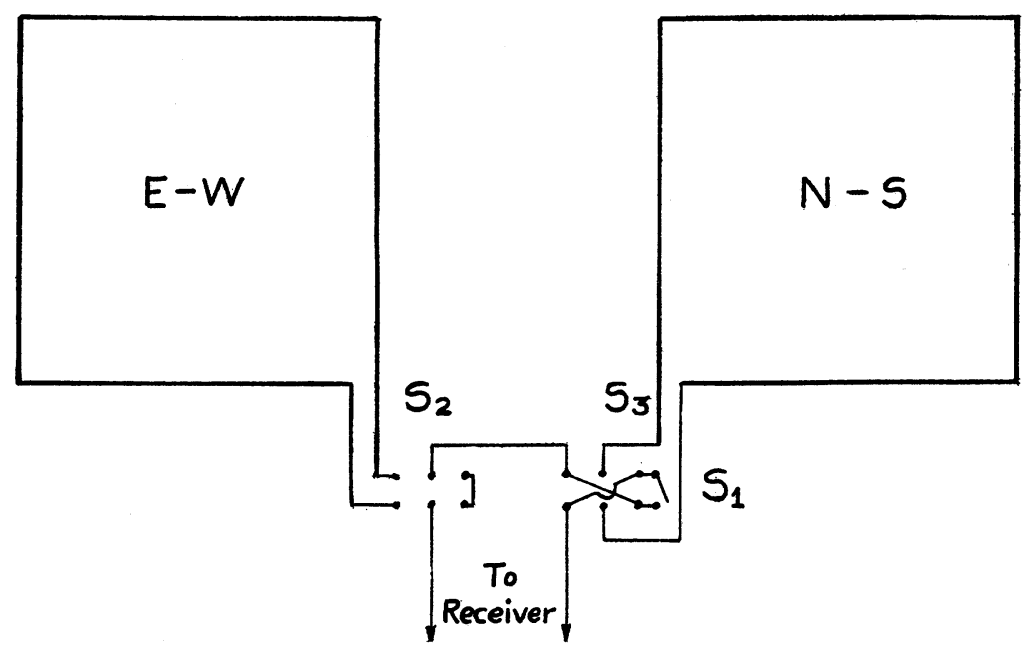

Figure 2-Double Loop Arrangement

For best results, the two rectangles should be separated so as to cut no common flux, altho this was not done in the experiments here described.

With a single rectangle of 16 turns, a loading coil was used above 3,500 meters, and also with two rectangles above 5,000 meters. A larger and variable number of turns on the rectangle will permit the omission of the loading inductance and a maximum reception at all waves. The latter is of no great advantage after a certain number of turns have been reached, as the gain in signal strength is no longer proportional to the number of turns. Sayville, distant 1,170 miles $(1,885 \mathrm{~km}$.), could be read with 5 turns, on one rectangle, in the evening, during April.

Reception with the rectangles was compared from time to time with reception on the regular set at Grand Forks, using the 800 -foot (243 meters) three-wire antenna the far end of which is 120 feet ( 37 meters) high, and near end 60 feet (18 meters) high. Altho the signals at Grand Forks are very much louder, 
they are, with few exceptions, not so readable thru the summer strays.

The advantage of the set here described may be summarized as follows; it is cheap; compact; immune from storm damage; sufficiently sensitive; thoroly reliable; simple in adjustment; and, by its directivity, partially eliminates strays and reduces interference. Moreover, it is readily concealed, if, for military or other reasons, it is desirable to do so.

SUMMARY: A closed 3-meter square loop of 16 turns of wire, hung about 1.5 meters from the ground, was used for long distance reception with an oscillating audion. Daylight overland reception from stations as distant as 3,000 miles (4,800 kilometers) was regularly accomplished.

A combination of two similar loops was also employed, and considerably increased the directional selectivity.

The inherent directional qualities of these receivers were utilized in the reduction of strays and interference. 